\title{
FIREARM INJURY AND DEATH IN NSW
}

\section{Rebecca Peters*}

Coalition for Gun Control

\section{Gerard Fitzsimmons ${ }^{\dagger}$ and Ru Nguyen \\ Epidemiology and Surveillance Branch}

This paper describes the problem of serious injuries and deaths caused by firearm injuries in NSW. It summarises the data describing deaths and hospital separations due to firearm injuries for the state. It also outlines the provisions of the current gun law, which contains specific powers for health professionals.

The Port Arthur massacre in Tasmania on 28 April 1996 led to the comprehensive reform of Australia's gun laws. All state and territory governments agreed to pass laws that would provide an integrated firearm licensing and registration scheme to meet uniform national standards. The new NSW gun law, legislated as the Firearms Act 1996, came into effect on 1 July 1997. The law recognises firearm violence as a public health issue and emphasises prevention by:

- allowing gun ownership only by adults who prove themselves 'fit and proper persons', including the requirement to prove a genuine reason for gun ownership

- prohibiting self-loading rifles and shotguns except in very restricted circumstances

- requiring all guns to be registered and banning private sales of guns

- requiring a 28-day waiting period before the purchase of each gun.

\section{THE SIZE OF THE PROBLEM}

During the five calendar year period from 1990 to 1994 , 824 deaths by firearms were recorded in NSW (an average of 165 deaths per year). In addition, during the financial years 1990-91 through 1994-95, 995 people were hospitalised because of firearm injuries. Of these, 79 died in a hospital. This indicates 1740 serious firearm injuries during a five-year period, or around 350 injuries each year. These data do not include firearm injuries for which other medical help was sought, nor do they include injuries that were not medically treated.

\section{FIREARM INJURIES AND DEATHS}

\section{Deaths}

For the five calendar year period described, firearms were the fifth major cause of injury death in NSW (824, or seven per cent), after motor vehicle crashes (3329), falls and fractures (1932), poisoning (1855), and hanging-

\footnotetext{
* Currently with the Open Society Institute, New York.

$\dagger$ Currently with the Australian Institute for Health and Welfare, Canberra.
}

suffocation (1117). As Figure 1 shows, the majority of firearm deaths resulted from intentional shootings: 626 (76 per cent) were suicides, 145 (18 per cent) were homicides and 36 (four per cent) were accidents. The remainder were deaths that involved legal intervention (police shootings) or were deaths of undetermined intent.

Firearm death rates have declined since 1985 . The ageadjusted firearm death rate (per 100,000) was 4.2 in 1985 and 2.4 in 1994. In 1994, the rate for males was 4.4 per 100,000 and for females was 0.5 per 100,000 . The rates of male deaths and female deaths have reduced at about the same rate.

\begin{abstract}
Hospital separations
Hospital separations due to firearm injuries have also dropped consistently over the five-year period. The figure for 1994-95 was 159, a 36 per cent decline from the 1990-91 figure of 250. The average number of separations was 199 per year. The age-adjusted rate of firearm-related hospitalisations per 100,000 dropped from 3.0 in 1988-89 to 2.4 in 1995-96 (Figure 2). There were regional differences in firearm-related hospitalisations. Rural areas had significantly higher rates than the state average, and some metropolitan or outer metropolitan areas (North Sydney, South Eastern Sydney and Wentworth) had significantly lower rates.
\end{abstract}

The 995 inpatient admissions during the financial years 1990-91 through 1994-95 occupied 7338 bed days, an average of 7.4 days per patient. As with firearm deaths, males accounted for 90 per cent of these admissions.

\section{INTENT INVOLVED IN INJURIES}

\section{Self-inflicted injuries}

Of all serious firearm injuries, the largest category was self-inflicted injury. Eighty-six per cent of these attempts at suicide resulted in death, approximately 125 each year. These firearm deaths constituted 21 per cent of all suicides in NSW from 1990 through 1994. The overwhelming majority of self-inflicted firearm injuries were to males (95 per cent).

\section{Assaults}

About 54 people each year were seriously injured with a firearm by another person (not counting police shootings). These assaults accounted for 16 per cent of all serious firearm injuries, 13 per cent of hospitalisations, and 18 per cent of deaths. The ratio of male to female victims was 3:1 among firearm assaults; however, in those cases resulting in death the ratio was $2: 1$. There were two age groups in which none of the victims survived their injuries: those aged 0 to 14 and those aged 65 or older.

\section{Unintentional shootings}

Unintentional shooting is usually the third largest category of firearm deaths, and the second largest category of firearm injuries, counting non-fatal injuries. By combining the 


\section{FIGURE 1}

FIREARM DEATHS BY INTENT IN NSW, 1990 TO 1994 (CALENDAR YEARS)

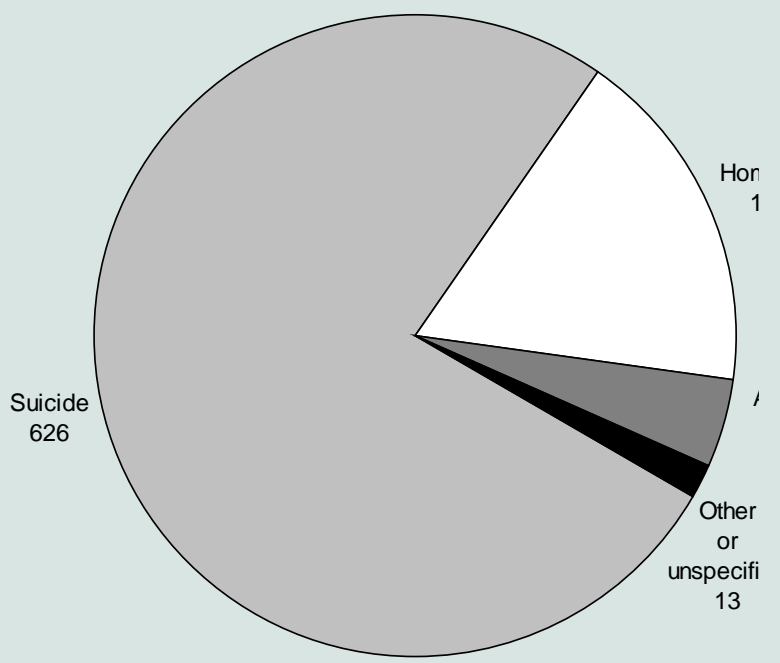

Note: Firearm injury was classified according to the ICD9 external cause codes E922, E955.0-955.4/9, E965.0-965.4, E970 and E985.0-985.4. Data excludes persons whose sex was unknown.

Source: ABS mortality data (Health Outcomes Information and Statistics Toolkit), Epidemiology and Surveillance Branch, NSW Health Department.

\section{FIGURE 2}

HOSPITAL SEPARATIONS FOR FIREARM INJURY IN NSW, BY SEX, 1989-90 THROUGH 1995-96 (FINANCIAL YEARS)

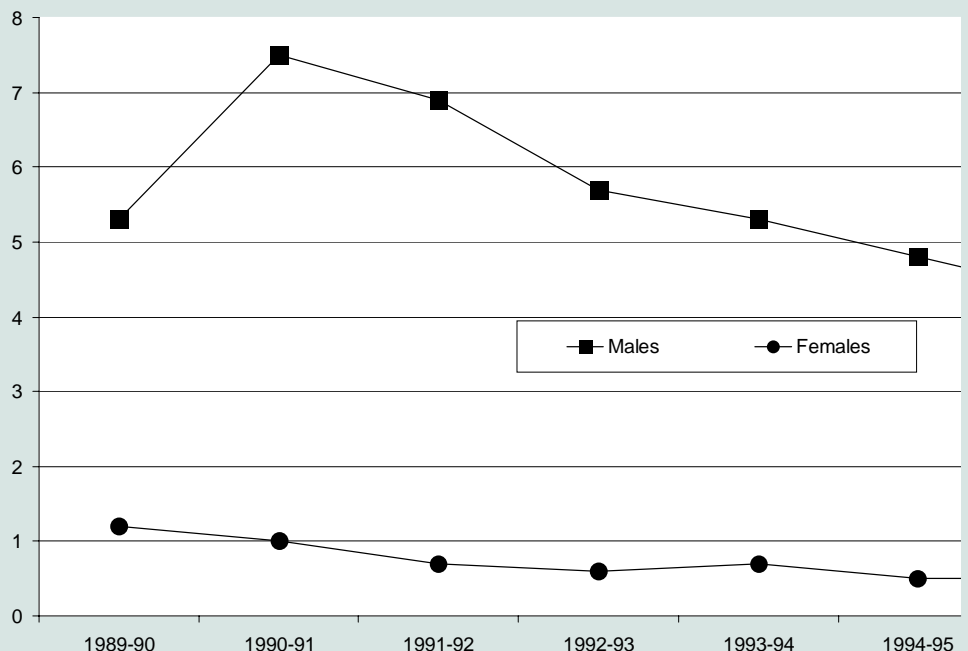

Note: Firearm injury was classified according to the ICD9 external cause codes E922,

E955.0-955.4/9, E965.0-965.4, E970 and E985.0-985.4. NSW population estimates as at 31 December each year. Hospital separation rates were age-adjusted using the Australian population as at 30 June 1991. Hospital separations in 1995-96 do not include NSW residents treated in Victoria, South Australia, Western Australia or Queensland.

Source: NSW Health Department Inpatient Statistics Collection and ABS population estimates (Health Outcomes Information and Statistics Toolkit), Epidemiology and Surveillance Branch, NSW Health Department. 
figures for the five years of hospital separations and mortalities, the data show that about 117 people were seriously injured in accidental shootings each year. Both deaths and hospitalisations from accidental shootings declined over the early 1990s. Hospitalisations dropped from 137 in 1990-91 to 78 in 1994-95, and deaths dropped from 10 in 1990 to two in 1994.

Similar to the pattern in self-inflicted shootings, 90 per cent of accidental injuries and 94 per cent of deaths involved males. In the five-year period, only two females died as the result of accidental shooting.

\section{Undetermined intent}

About one in 11 serious firearm injuries were of 'other' or 'undetermined' intent. These injuries, which include a small number of police shootings, accounted for nine per cent of all injuries, 15 per cent of hospitalisations and two per cent of deaths.

\section{GENDER DIFFERENCES}

Nine out of ten people seriously injured or killed with a firearm were male. Male victims made up 95 per cent of victims with self-inflicted injuries and 96 per cent of completed suicides, 74 per cent of assaults and 65 per cent of homicides, 90 per cent of accidental injuries and 94 per cent of accidental deaths.

\section{TYPES OF FIREARMS}

The Australian Bureau of Statistics (ABS) reported the types of guns that caused deaths in 625 (76 per cent) cases in NSW in the period from 1990 through 1994. Of these, 393 (63 per cent) involved hunting rifles, 193 (28 per cent) shotguns, 45 (seven per cent) handguns and 14 (two per cent) military rifles.

\section{DISCUSSION}

Firearms are an important cause of injury death in NSW (especially as a component of male suicides) with nearly half of all serious firearm injuries resulting in death. Rates of firearm injuries, both fatal and non-fatal, are several times higher in the inland rural regions than in Sydney. In this respect, firearm injury follows the pattern of injury generally.

Gunshot wounds can be distinguished from other injuries in that the victims' chances of dying are extremely high. The high level of mortality among victims of gunshot wounds has been noted in the public health literature. A study of patients admitted to Westmead Hospital in the early 1980 s found that the mortality rates among gunshot victims was 3.4 times that of stabbing victims. ${ }^{1}$ This study included self-inflicted injuries and injuries resulting from assault. The authors noted that, although victims who were stabbed were more likely to have multiple wounds (having been stabbed or slashed more than once), gunshot wounds caused far more damage to organs. A study of domestic assaults in the United States found a similar result: ${ }^{2}$ assaults involving guns were three times more likely to result in death than assaults with knives; 23.4 times more likely than unarmed assaults; and 12 times more likely than nonfirearm assaults in general.

The lethal nature of these injuries justifies the public health community's interest in this area for the purpose of prevention. If every second serious firearm injury is likely to end in death, then the benefits from preventing these injuries are great, not only in saving lives but also in avoiding disability, suffering and costs.

While firearm injury is primarily a male problem, an examination of the data by gender and intent reveals a striking difference between male and female injuries. Male firearm injuries are primarily accidents or suicide attempts, whereas female injuries result from assaults. Research on interpersonal violence has shown that women are most likely to be assaulted or killed by a member of their own family. ${ }^{3,4}$ The greatest potential to reduce gun deaths among males may lie in the prevention of suicides using firearms; for female victims, the emphasis should be on preventing domestic violence.

This distribution of mortality-morbidity by intent is another reason why firearm injury is a public health issue in NSW and in Australia generally. Suicide and domestic violence sit squarely within the current National Health Priority Areas of injury and mental health and lend themselves to a preventive public health approach.

Gun control laws aim to prevent firearm injuries by reducing the availability of firearms generally, and especially to people who are likely to misuse them. Firearms are more prevalent in rural areas. For example, in the 1994 NSW Health Promotion Survey, 26 per cent of rural respondents said they had a gun on their property, compared with seven per cent of urban respondents. ${ }^{5}$

Research on the ownership of firearms involved in injuries is sparse. However, a New Zealand study of gun homicides found that most victims were killed by licensed gun owners. This suggests that guns were easily available. ${ }^{6}$ A study of men surviving self-inflicted gunshot wounds undertaken by Westmead Hospital suggested that the immediate availability of a gun affected the choice of method of attempting suicide. ${ }^{7}$ Although information on the source of the gun was not always available, none of the patients were recorded as having bought a gun specifically for the purpose of attempting suicide. These studies suggest that shootings may often involve guns that come easily to hand at the moment when high emotion turns to violence.

The distribution of injuries among gun types in the NSW data also points to an association between availability and misuse. The ratio of deaths caused by rifles, shotguns and handguns was approximately 6:3:1, respectively, which corresponds roughly to the proportions in which these firearms are owned in the Australian states and territories where records of firearm ownership are available. 
This suggests that the involvement of guns in serious injury reflects their availability in the community. In other words, the more common a particular type of gun, the more likely it is to be used in violence.

Rates of both deaths and hospital separations due to firearm injuries have declined in NSW over the past decade. The decline in injuries may reflect:

- a drop in gun ownership (although the lack of a firearm registration system made gun ownership impossible to measure)

- $\quad$ strict laws on guns and domestic violence (since 1992 in NSW)

- an increasing safety-consciousness among gun owners brought about by the intense public debate on gun control after mass shootings in the 1980s

- declining cultural acceptability of firearms may have contributed to the drop in this choice of method for suicide (accompanied by an increase in hangings).
The data reported in this article do not include the period since the commencement of the NSW Firearms Act 1996, with the high level of publicity and discussion that heralded its introduction. The law aims to reduce the overall number of guns in the community, as well as reducing the number of guns in individual households. However, it is expected that the Act will also create an opportunity to further reduce the level of firearm injuries in NSW.

Health professionals have an important role to play in supporting the new law because it provides a specific power for health professionals to help police decide whether a particular individual should be allowed to own guns. Under S79 of the Act and R97 of the Firearms (General) Regulations 1997, doctors, psychologists, nurses and counsellors may inform the police if they are of the opinion that a patient is an unsuitable person to be in possession of a firearm:

\section{The new gun law}

On 1 July 1997, the Firearms Act 1996 came into force in NSW. The new law implements the national gun control standards agreed to by the Australasian Police Ministers Council (APMC) after the Port Arthur massacre. Within the new law, the possession and use of firearms is confirmed as 'a privilege that is conditional on the overriding need to ensure public safety'. One of the main elements of the law is that a licence is required for civilian acquisition or possession of any gun. Licence criteria include:

- minimum age 18 (junior permits are available for children aged 12 to 18 to shoot under supervision)

- applicants must prove a genuine reason for owning guns (membership of a target club, having permission to hunt on private land, being a farmer or professional shooter, etc.)

- screening for criminal record, domestic violence, past self-harm

- minimum 10-year ban for domestic violence and certain other offenders (violence, drugs)

- police may reject licence application in the public interest.

In addition, five categories of firearms (A, B, C, D, $H$ ) based on type of gun and magazine capacity have been created. Further license criteria include:

- proof of need for any guns other than Category A

- occupational need must be shown in the case of self-loading rifles and shotguns (categories $\mathrm{C}$ and D).

The new Firearms Act also introduces the following provisions:

- maximum five-year duration for licences
- police must cancel licences and seize guns from households in which domestic violence occurs

- doctors, nurses, psychologists and counsellors may report patients who are unsuitable to possess guns

- all guns must be registered on transfer of ownership

- private and mail-order sales of guns are banned, which means that all sales must be through dealers

- a permit is required to acquire each gun, with proof of genuine reason and/or genuine need

- strict national standards for locked storage of guns and ammunition apply

- safety training is required for first-time licence applicants

- reciprocal recognition of interstate licences

- severe penalties for breaching the law.

The new gun law takes a preventive approach. It aims to restrict the availability of firearms generally by permitting gun ownership only by people who prove a genuine reason. It also aims to ensure that the individuals who have shown themselves unsuitable to possess guns are identified. There is no limit on the number of guns one person can own, but the requirement to prove genuine reason for each permit-to-acquire will make it more difficult to build arsenals.

Although the power to regulate firearms lies with the states and territories, the Commonwealth Government has also played a role. It prohibited the importation of Category $C$ and D weapons (selfloading rifles and shotguns) and funded the national buyback, which collected and destroyed more than 640,400 of these guns. 
- because of the patient's mental condition

- because the practitioner thinks that the patient might attempt suicide or would be a threat to public safety if in possession of a firearm.

Further roles for health professionals in addressing this public health problem are as credible advocates for community safety; implementing improvements in coding and collecting data; and responding to the call for further research on the circumstances of firearm injuries, both fatal and non-fatal. The skills and resources of the public health community allow its members to make a major contribution in monitoring and evaluating the legal changes that have occurred.

\section{REFERENCES}

1. Wolfenden H, Dean S. Gunshot wounds and stabbings: Experience with 124 cases. Australian \& New Zealand Journal of Surgery 1987; 57: 19-22.

2. Saltzman SE, Mercy JA, O'Carroll PW, Rosenberg ML, Rhodes PH. Weapon involvement and injury outcomes in family and intimate assaults. JAMA 1992; 267(22) 10: 30433047.

\section{Methods used in this analysis}

Firearm-related hospitalisations were recorded by the NSW Inpatient Statistics Collection (ISC) for the financial years from 1989-90 to 1995-96. The ISC is maintained by the NSW Health Department's Information and Data Services Branch. It consists of demographic and clinical information collected on separation (discharge, transfer or death) from all NSW public, private and Department of Veterans Affairs hospitals and public nursing homes. Firearm deaths for the calendar years from 1985 to 1994 were recorded by the Australian Bureau of Statistics (ABS) Mortality Collection.

Both datasets were accessed via the Health Outcomes Information and Statistics Toolkit (HOIST) of the Epidemiology and Surveillance Branch, NSW Department of Health.

Firearm-related hospital separations and deaths are coded using the ninth revision of the International Classification of Diseases (ICD9) by the External Cause Code (E-code). The E-code defines the cause that best accounts for inpatient care or death in the respective collections. These codes describe both motive and type of gun involved in the injury. Air gun injuries are excluded because these guns are not assigned an identifying code by ICD9. Codes were selected for firearm-related injury to assess mortality and morbidity. They included:
E922-E922.9
Accident caused by firearm
E955.0-E955.4 Suicide caused by firearm and $E 955.9$
E965.0-E965.4 Assault caused by firearm
E970-E970.9 Injury due to legal intervention caused by firearms

\author{
E985.0-E985.4 Injury by firearm, undetermined \\ whether accidentally or \\ purposefully inflicted.
}

The analysis of death data used ABS population estimates at 31 December for the years 1985 to 1995 by age, sex and statistical local area. The analysis of ISC hospitalisation data used ABS population estimates at 30 June for the years 1989 to 1995 by age, sex and statistical local area. The Area Health Service boundaries at 31 May 1997 were used to present a comparison of different geographically defined population groups across NSW.

The crude death rate is an estimate of the proportion of a population that dies in a specified period. We expressed our rates as per 100,000 population. This method does not account for the different age structures of a population and can be misleading when examining long-term trends or comparisons between geographic areas.

The directly age standardised rate method accounts for differences in the age composition of the NSW and AHS populations. The method averages specific rates in a study population using the distribution of a specified population. We used the 1991 Australian standard population as our specified population. This standard rate represents the crude rate in the study population as though it had the same age distribution as the 1991 Australian standard population. The same population was used for both males and females to allow valid comparisons of age-standardised rates between the sexes. 
3. Australian Bureau of Statistics. Women's Safety Australia 1996. Canberra: ABS, 1996.

4. James M, Hallinan J. Homicides in Australia 1992-93. Trends \& Issues, No. 51, Aust Institute of Criminology, 1995.

5. NSW Health Department. NSW Health Survey 1994.

6. Alpers P, Morgan B. Firearm Homicide in New Zealand:
Victims, perpetrators and their weapons 1992-94. Paper presented at the National Conference of the Public Health Association of New Zealand, Dunedin, 28 June 1995.

7. De Moore GM, Plew JD, Bray KM, Snars JN. Survivors of self-inflicted firearm injury: A liaison psychiatry perspective Med J Aust 1994; 160: 421-5. W

\section{CHILDHOOD INJURY SURVEILLANCE: THE VALUE OF EMERGENCY DEPARTMENT DATA}

\author{
Meredith Nirui, Valerie Delpech, Mark Ferson \\ South Eastern Sydney Public Health Unit

\section{Linda Christie} \\ South Eastern Sydney Area Health Service
}

This article examines child injury data from the Sydney Children's Hospital Emergency Department database for an 11-month period. The database provides useful local information about the nature, location and type of injuries sustained by children that is essential for effective local planning of injury prevention initiatives.

\section{INTRODUCTION}

Injury has been identified as a priority area for the health system at all levels. It is a leading cause of premature death in Australia and was the fourth highest cause of mortality in NSW in 1994. ${ }^{1}$ From 1991 to 1995 , injury was the third leading cause of hospital separations among South Eastern Sydney (SES) residents, representing eight per cent of admissions. ${ }^{2}$ However, mortality and inpatient data describing injury are limited. The emergency department (ED) is an appropriate setting to study the location of injuries on the body and where the event took place.

Despite a number of initiatives at state and national levels, there is currently no consistent approach to the collection of injury data by emergency departments. In 1990 the National Injury Surveillance Unit (NISU) of the Australian Institute of Health and Welfare introduced the Injury Surveillance Information System (ISIS) to collate data on ED injury presentations at a national level. While ISIS data provided a better understanding of the context of injuries, it was labour-intensive and implemented in a nonrepresentative sample of 50 hospitals. Therefore, it was not able to provide incidence rates. In 1996, the NSW Department of Health introduced the Emergency Department Information System (EDIS). This involves recording of ED presentations electronically. At this stage EDIS has been implemented in an abbreviated form and in a limited number of EDs across NSW.
To assess the completeness and value of the EDIS database and thus its potential to contribute to the study of childhood injuries, we examined the EDIS injury data (January-November 1996) collated by the Sydney Children's Hospital, the major paediatric referral hospital serving the south eastern area of Sydney. During the 1996 calendar year, 21 per cent of all ED presentations at the Sydney Children's Hospital were due to injury.

\section{METHODS}

Between January and November 1996, parents of children up to the age of 15 years presenting with an injury to the ED of the Sydney Children's Hospital were asked to complete a detailed questionnaire including their demographics and information on the injury sustained. The data were entered into the EDIS database by an Injury Surveillance Officer. Completeness of the data was largely dependent upon parental consent and cooperation and is estimated to be 80 to 85 per cent complete. Data were analysed by gender, age group ( 0 to 4 years, 5 to 9 years and 10 to 14 years), cause, place, and type of injury, using SPSSv8 for Windows and Epi-Info v6. Severity of injury was assessed using E-codes.

\section{RESULTS}

Over the 11-month study period, data on 2549 children (1006 girls, 1543 boys) up to age 15 were recorded in the EDIS injury database. Children aged 0 to 4 years accounted for 38 per cent of presentations, compared to 35 per cent and 27 per cent in the 10 to 15 years and 5 to 9 years age groups, respectively (mean $=7$ years). The male to female ratio for all ages was 1.5:1. More boys were represented in all age groups, but a significant higher proportion of boys presented among 10 to 15 year olds (male to female ratio $=1.9: 1, \mathrm{OR}=1.43, \mathrm{CI}=1.20-1.69$ ).

\section{Cause of injury}

More than half of injury presentations were due to falls (Table 1). Younger age groups were more likely to present with a fall $(\mathrm{p}=0.02)$. Falls from low height falls $(<1$ metre or same level) accounted for the majority (88.4 per cent) of 